Revista Española de

I $\mathrm{n}$ ve s t ig a c i ó $\mathrm{n}$

Criminológ i c a

\title{
Editorial
}

Santiago Redondo Illescas

Editor-jefe REIC

Universidad de Barcelona

\section{Presente y futuro de la REIC}

La Revista Española de Investigación Criminológica (REIC) se ha ido consolidando, desde su nacimiento en 2004, como una de las publicaciones periódicas en Criminología más importantes en lengua española. Y actualmente es una revista criminológica ampliamente conocida y reconocida en los ámbitos académicos y profesionales. El mérito de ello corresponde en buena medida a los excelentes editores con los que ha contado la REIC a lo largo de sus catorce años de andadura: Juan José Medina (U. de Manchester), Vicente Garrido (U. de Valencia), César San Juan (U. del País Vasco) y Josep Cid (U. Autónoma de Barcelona). Durante todo este tiempo, nuestra revista ha publicado decenas de artículos y monografías sobre ámbitos criminológicos variados y punteros como delincuencia juvenil, delitos económicos, carreras delictivas, violencia, delincuencia sexual y de género, terrorismo, victimización, política criminal, seguridad ciudadana, tratamiento, reincidencia, prevención... Como resultado de todo ello, la REIC tiene una buena acogida nacional e internacional por parte de profesores, trabajadores de la justicia y estudiantes de Criminología y otras ciencias afines. Y sus artículos son constantemente consultados por investigadores y profesionales, y referenciados en múltiples estudios. Además, la 
Revista cuenta también con el aval científico que se deriva de su inclusión en diversos índices de calidad como InDret, Latindex, DICE, IN-RECJ y CARHUS Plus. Lo que significa que la publicación de estudios en la REIC es reconocida como un mérito académico contrastado.

A partir del número 14 (de 2016), de acuerdo con el encargo recibido de la Sociedad Española de Investigación Criminológica, me cumple el honor y el reto de asumir la responsabilidad de Editor-jefe de la REIC. Responsabilidad para la que afortunadamente podré seguir contando con el consejo y la ayuda de los distinguidos profesores que me han precedido en esta tarea. Como puede verse, es mucho el camino editorial ya andado por nuestra revista; pero, sin duda, son muchos también los retos pendientes. Tal vez uno de los más importantes sea la expansión y consolidación de la REIC en el plano criminológico internacional. Para ello, un objetivo necesario es la apertura de nuestra revista a la publicación cada vez más frecuente de trabajos científicos en lengua inglesa. En este número 14 ya iniciamos esta nueva singladura con la publicación de varios trabajos en inglés. De este modo, es esperable que nuestra revista pueda encontrarse y confluir en mayor grado con otras publicaciones criminológicas internacionales y con los equipos de investigación más punteros en Criminología, muchos de los cuales radican en Estados Unidos, Inglaterra y otros países que utilizan el inglés como vehículo prioritario de difusión criminológica.

No obstante, siendo la combinación editorial del castellano y del inglés un desafío futuro importante, para el fortalecimiento de nuestra revista el mayor desafío de todos continúa siendo la mejora creciente de nuestra calidad como publicación criminológica especializada, ya sea en castellano o en inglés. Y ello concierne tanto a la recepción de manuscritos de alto nivel científico como también a la eficiencia de los procesos de revisión crítica de dichos manuscritos por expertos anónimos. Así como a una paulatina mejora y a una convergencia progresiva de nuestro proceso editorial (recepción y revisión de artículos, maquetación y publicación) con los sistemas y patrones internacionales. 
En dirección a esta mayor consolidación y universalización de la Revista Española de Investigación Criminológica, quiero finalmente animar en este Editorial, a investigadores y profesionales de la Criminología, a considerar nuestra revista como un medio idóneo y de alto impacto social y académico para el envío de sus aportaciones científicas. 